\title{
Potencialidades no uso de imagens termais aéreas de alta resolução da superfície urbana como ferramenta para mapear o campo térmico
}

High spatial resolution thermal aerial imagery support urban forest design

\author{
F. H. Mendes ${ }^{1 *}$; J. L. Polizel ${ }^{1}$; C. Hamamura ${ }^{1}$; M. D. Baptista ${ }^{1}$; D. F. Silva Filho ${ }^{1}$ \\ ${ }^{I}$ Departamento de Ciências Florestais/Laboratório de Métodos Quantitativos/Setor de Arborização Urbana, Escola \\ Superior de Agricultura "Luiz de Queiroz", Universidade de São Paulo, CEP 13418-900, Piracicaba-São Paulo, \\ Brasil
}

*friquemendes@usp.br

(Recebido em 12 de maio de 2015; aceito em 13 de julho de 2015)

\begin{abstract}
O presente trabalho apresenta a potencialidade no uso de imagens termais aéreas de alta resolução da superfície urbana como ferramenta para mapear zonas de conforto térmico. Utilizou-se uma câmera termal de alta resolução, modelo FLIR SC660, com resolução espacial de 1,5 m e espectral de 640x480 pixels, em sobrevoo na área urbana do município de Piracicaba, São Paulo, Brasil, durante o dia 30 de outubro de 2012, em três períodos: 08:36 (manhã), 14:27 (tarde) e 19:23 (noite), horário local. No Brasil, ainda são poucos os trabalhos realizados com imagens termais de alta resolução em levantamentos aéreos. Por meio de técnicas de sensoriamento remoto das imagens obtidas, foi possível identificar o campo térmico na área de estudo sob influência, principalmente, do asfalto, classe com temperatura de superfície mais alta $\left(55,7^{\circ} \mathrm{C}\right.$ às $\left.14: 27\right)$, e vegetação e corpos d'água, as quais minimizaram o efeito.

Palavras-chave: clima urbano, imagens termais de sobrevoo, temperatura de superfície
\end{abstract}

This paper presents the potentiality in the use of high-resolution thermal aerial images on urban surfaces as a tool to map thermal comfort zones. We used a high-resolution thermal camera FLIR SC660 model with spatial resolution of $1.5 \mathrm{~m}$ and spectral of $640 \times 480$ pixels, overflight in the urban area on the Piracicaba city, São Paulo state, Brazil, during the October $30^{\text {th }}$ 2012, into three periods: 08:36 a.m. (morning), 02:27 p.m. (afternoon) and 07:23 p.m. (evening), local time. In Brazil, there are few studies carried out with high-resolution thermal images in aerial surveys. Through remote sensing of the images obtained, it was possible to identify the thermal field in the study area, influenced, mainly, by the asphalt class, with higher surface temperature $\left(55.7{ }^{\circ} \mathrm{C}\right.$ at $02: 27$ p.m.), and the vegetation and water bodies, which minimized the effect.

Keywords: urban climate, thermal images from overflight, surface temperature

\section{INTRODUÇÃO}

As questões climáticas têm despertado interesses na sociedade, haja vista a interferência direta sobre a qualidade de vida e as consequências da contínua expansão e modificação do ambiente urbano.

De acordo com Oke (2006) [1], a necessidade por informações meteorológicas é crescente, sendo demandada no planejamento urbano, conservação de energia, transportes e comunicações, qualidade do ar e saúde, manejo de águas pluviais e do vento, segurança e medidas de emergência.

As interações entre superfícies e modificações atmosféricas provenientes da urbanização geralmente promovem ambientes termicamente modificados, com centros urbanos mais quentes que periferias, especialmente à noite. Esse fenômeno, conhecido como "ilha de calor", vem sendo estudado com auxílio do sensoriamento remoto e imagens de satélite [2]. A sensação de desconforto térmico causada pela temperatura do ar pode chegar a $7^{\circ} \mathrm{C}$ e mitiga-se alterando a cor do pavimento (aumento da refletância) ou tornando-o permeável [3].

A temperatura de superfície interfere diretamente nas condições climáticas da atmosfera urbana, entretanto, sua medição acaba sendo dificultada pela complexidade das interações, em virtude da variedade dos materiais presentes [4]. 
O balanço energético das cidades pode ser alterado por meio da adição de superfícies evaporativas, distribuindo de maneira homogênea a vegetação na área, visto que a radiação absorvida pode ser dissipada na forma de calor latente, minimizando a temperatura de superfície [5].

Dessa forma, o sensoriamento remoto aparece como ferramenta rápida e prática na identificação de locais de concentração de calor em áreas urbanas, contribuindo para o conforto térmico das pessoas [6].

Pesquisa realizada em Basel, Suíça, por Leuzinger et al. (2010) [7], estudou as temperaturas de superfícies de folhas em diferentes espécies arbóreas e concluiu que os valores das temperaturas dependem da localização das árvores, tamanho da folha, condutância estomatal e arquitetura da copa, sendo que raramente ultrapassaram $40^{\circ} \mathrm{C}$.

Visto a importância que as informações obtidas pelo sensoriamento remoto podem proporcionar, este estudo avaliou o potencial do uso de imagens termais aéreas de alta resolução para a caracterização do campo térmico urbano.

\section{MATERIAL E MÉTODOS}

O sobrevoo foi realizado no campus da Escola Superior de Agricultura "Luiz de Queiroz" (ESALQ/USP), localizado entre as coordenadas geográficas de $22^{\circ} 42^{\prime} 30^{\prime \prime} \mathrm{S}$ e $47^{\circ} 38^{\prime} 00^{\prime \prime} \mathrm{O}$, no bairro Agronomia, em Piracicaba, São Paulo, Brasil (Figura 1).

A câmera termal utilizada foi a de alta resolução, FLIR modelo SC660 (Figura 1), com resolução espacial de $1,5 \mathrm{~m}$ e espectral de $640 \times 480$ pixels, abrangendo faixa espectral de 7,5 a $13 \mu \mathrm{m}$, lente de $8 \mathrm{~mm}$ e campo de visão de $32^{\circ}$, com 3,2 Mpixel auto foco, full color e precisão de +/- $1{ }^{\circ} \mathrm{C}$ [8]. A faixa de abrangência da imagem, a $2000 \mathrm{~m}$ de altitude, foi de, aproximadamente, $1010 \times 752$ metros.

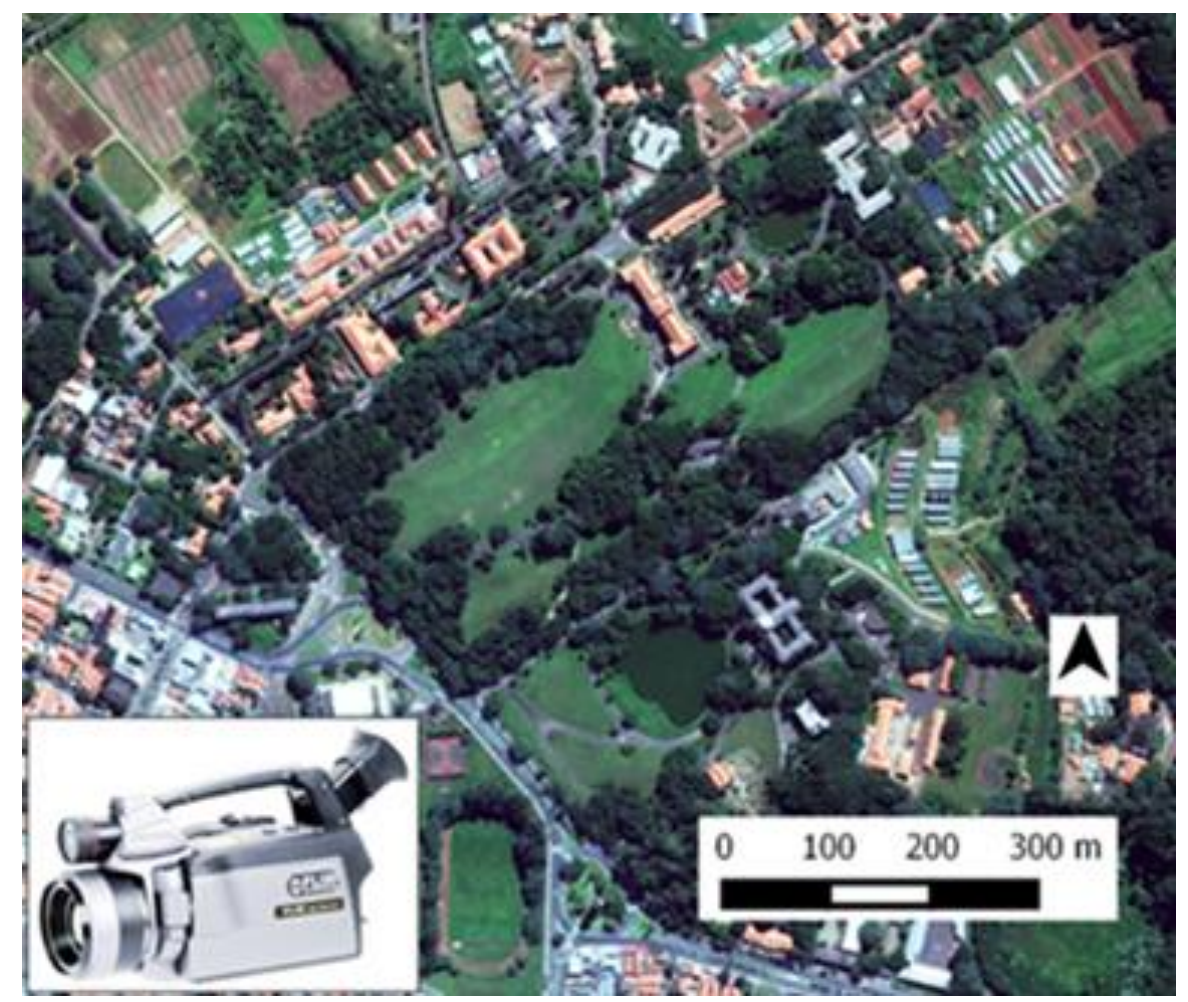

Figura 1: Imagem em cor verdadeira RGB (red, green, blue) da Escola Superior de Agricultura "Luiz de Queiroz" e a respectiva câmera termal FLIR SC660 (Fonte: adaptado de FLIR, 2015).

As imagens termais foram tiradas em três diferentes períodos do dia 30 de outubro de 2012: às 08:36, 14:27 e 19:23 (horário de Brasília e local). Segundo dados do posto meteorológico da ESALQ (Tabela 1), podemos considerá-lo um dia típico desta estação, ou seja, quente e seco. 
Tabela 1 - Dados do posto meteorológico da ESALQ para o dia 30 de outubro de 2012. (Fonte: Estação Automática da ESALQ/USP [9])

\begin{tabular}{ccccccc}
\hline Horário & $\begin{array}{c}\text { Temperatura do } \\
\operatorname{ar}\left({ }^{\circ} \mathrm{C}\right)\end{array}$ & $\begin{array}{c}\text { Velocidade do } \\
\text { vento }(\mathrm{m} / \mathrm{s})\end{array}$ & $\begin{array}{c}\text { Direção do } \\
\text { vento }\left({ }^{\circ}\right)\end{array}$ & $\begin{array}{c}\text { Radiação } \\
\text { solar }\left(\mathrm{W} / \mathrm{m}^{2}\right)\end{array}$ & $\begin{array}{c}\text { UR } \\
(\%)\end{array}$ & $\begin{array}{c}\text { Precipitação } \\
(\mathrm{mm})\end{array}$ \\
\hline $08: 30$ & 28,7 & 0,8 & 98,1 & 567,7 & 86,1 & 0,0 \\
$14: 30$ & 37,7 & 2,1 & 268,6 & 818,0 & 36,3 & 0,0 \\
$19: 30$ & 30,6 & 0,2 & 87,4 & 0,0 & 60,2 & 0,0 \\
\hline Média & 29,7 & 0,7 & 168,4 & 347,2 & 71,0 & 0,0 \\
\hline
\end{tabular}

As imagens termais foram processadas no software FLIR QuickReport versão $1.2 \mathrm{e}$ convertidas numa matriz numérica de 640 linhas x 480 colunas, com valores de temperatura de superfície $\left(\mathrm{em}^{\circ} \mathrm{C}\right)$ em cada célula, sendo que para cada pixel da imagem teve um valor de temperatura correspondido.

Posteriormente, as imagens foram carregadas no software livre Quantum Gis versão 1.7 (sistema de informação geográfica) e convertidas em escala de cinza (Figura 2), utilizando algoritmos de mínimo e máximo, obtendo valores de temperatura de superfície (em ${ }^{\circ} \mathrm{C}$ ) e georreferenciadas utilizando uma base de dados conhecida (Google Earth - WGS 84, zona 23 S).

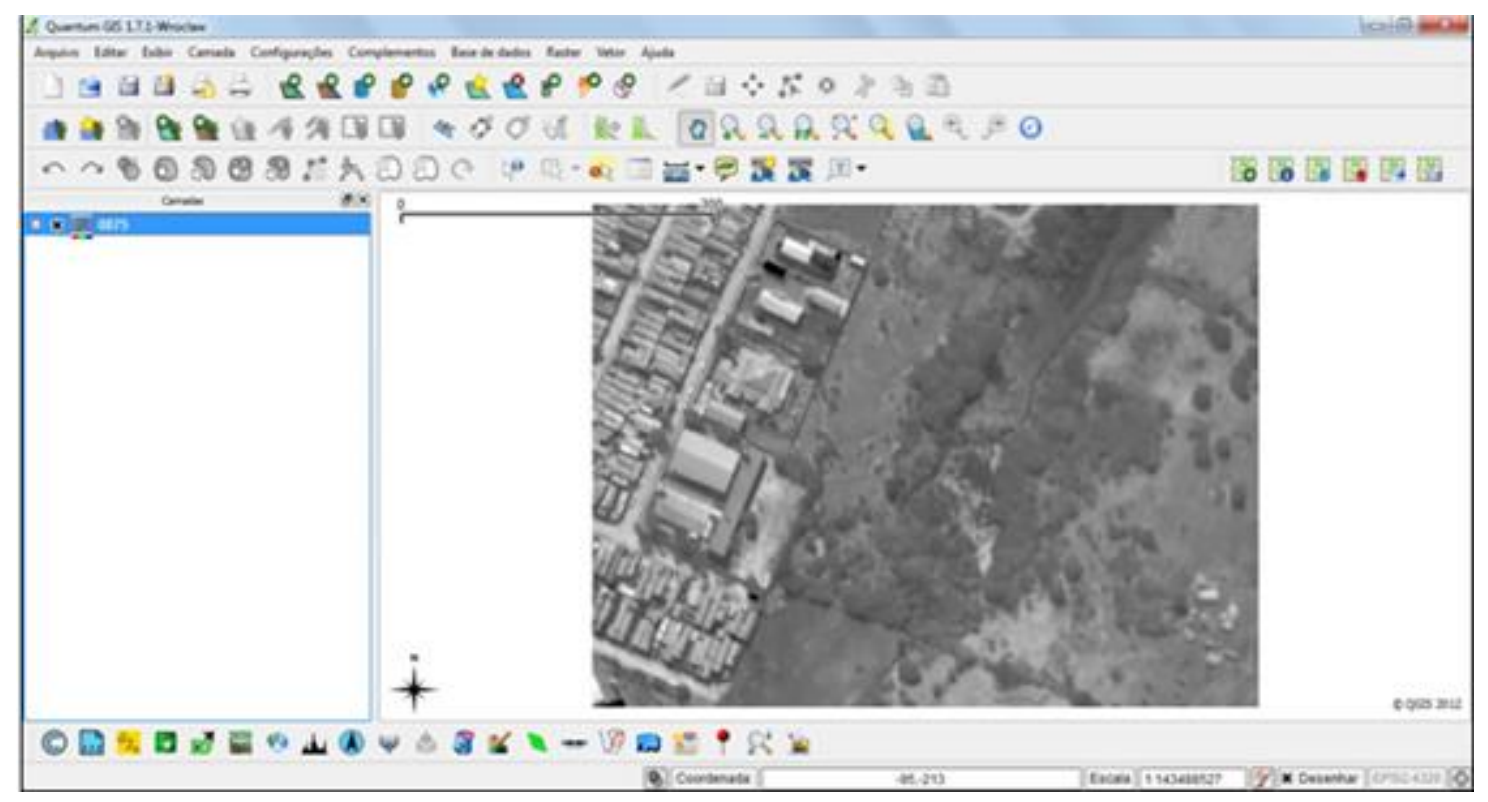

Figura 2: Matriz raster de temperatura de superficie 640x480 pixels, com as temperaturas em graus Celsius da superfície urbana, sendo que cada pixel dessa imagem corresponde a um valor de temperatura de superfície.

\section{RESULTADOS E DISCUSSÃO}

No período da manhã, às $08: 36$, pode-se notar que as maiores temperaturas aparecem nos locais cobertos por asfalto, cimento e telhas escuras, variando entre $45,0^{\circ} \mathrm{C}$ e $57,4{ }^{\circ} \mathrm{C}$, enquanto que as coberturas arbóreas, relvados e corpos d'água apresentaram temperaturas de superfície mais amenas, entre $15,3^{\circ} \mathrm{C}$ a $35,9^{\circ} \mathrm{C}$ (Figura 3 ). 


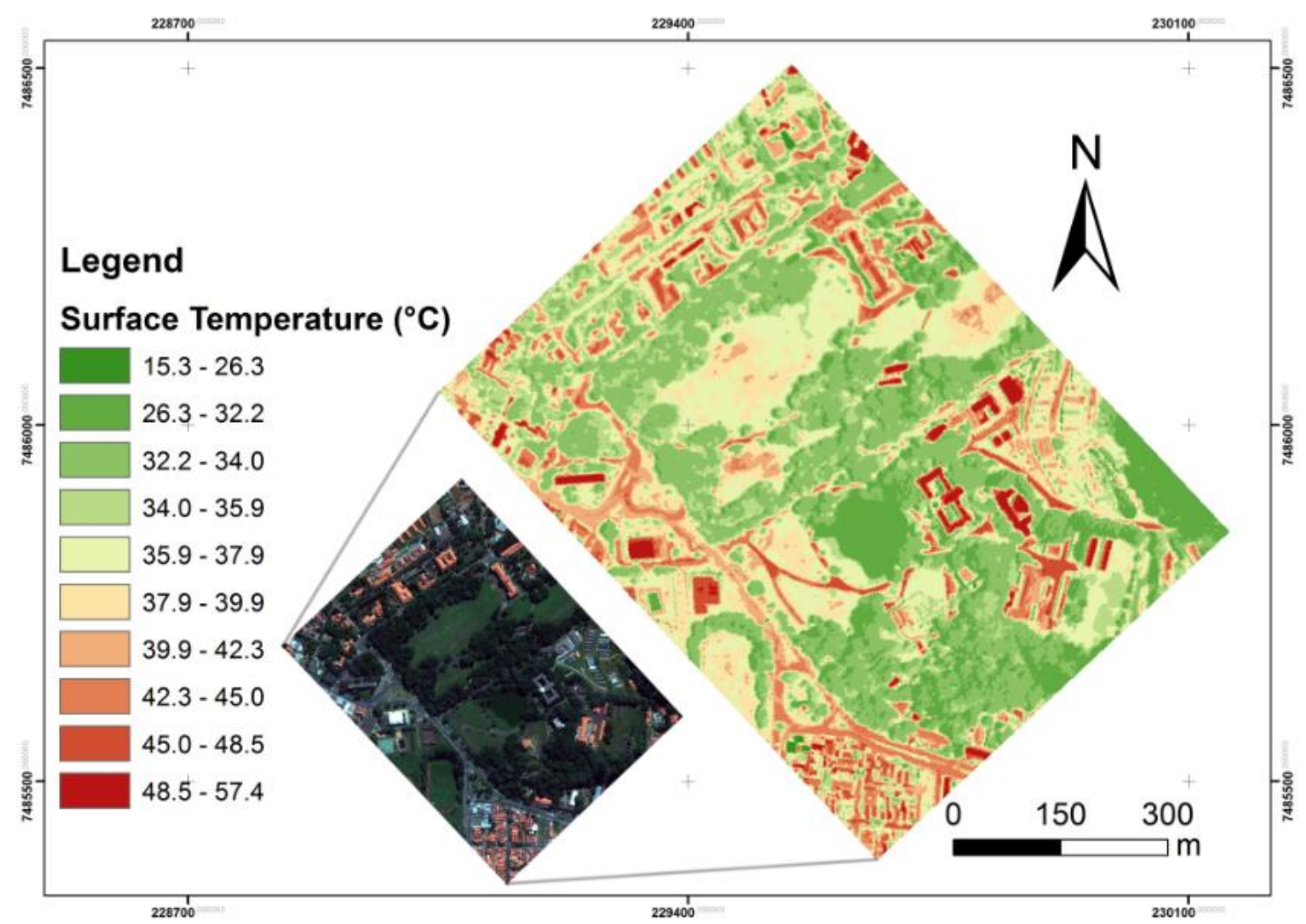

Figura 3: Mapa temático de temperatura de superfície às 8:36, na ESALQ/USP e arredores, destacando os maiores valores para o asfalto, cimento e telhas escuras, opondo-se a corpos d'água e vegetação.

Para o período da tarde, às 14:27, asfalto, cimento e telhas escuras ficaram entre $45,1{ }^{\circ} \mathrm{C} \mathrm{e}$ $55,7^{\circ} \mathrm{C}$, sendo o asfalto representado pelo maior valor, à medida que árvores, relvados e corpos d'água ficaram entre $14,2^{\circ} \mathrm{C}$ e $36,5^{\circ} \mathrm{C}$ (Figura 4). É importante destacar que, por se tratar de imagens em diferentes horários, a padronização das escalas dificultaria a visualização dos contrastes da variável climática estudada. 


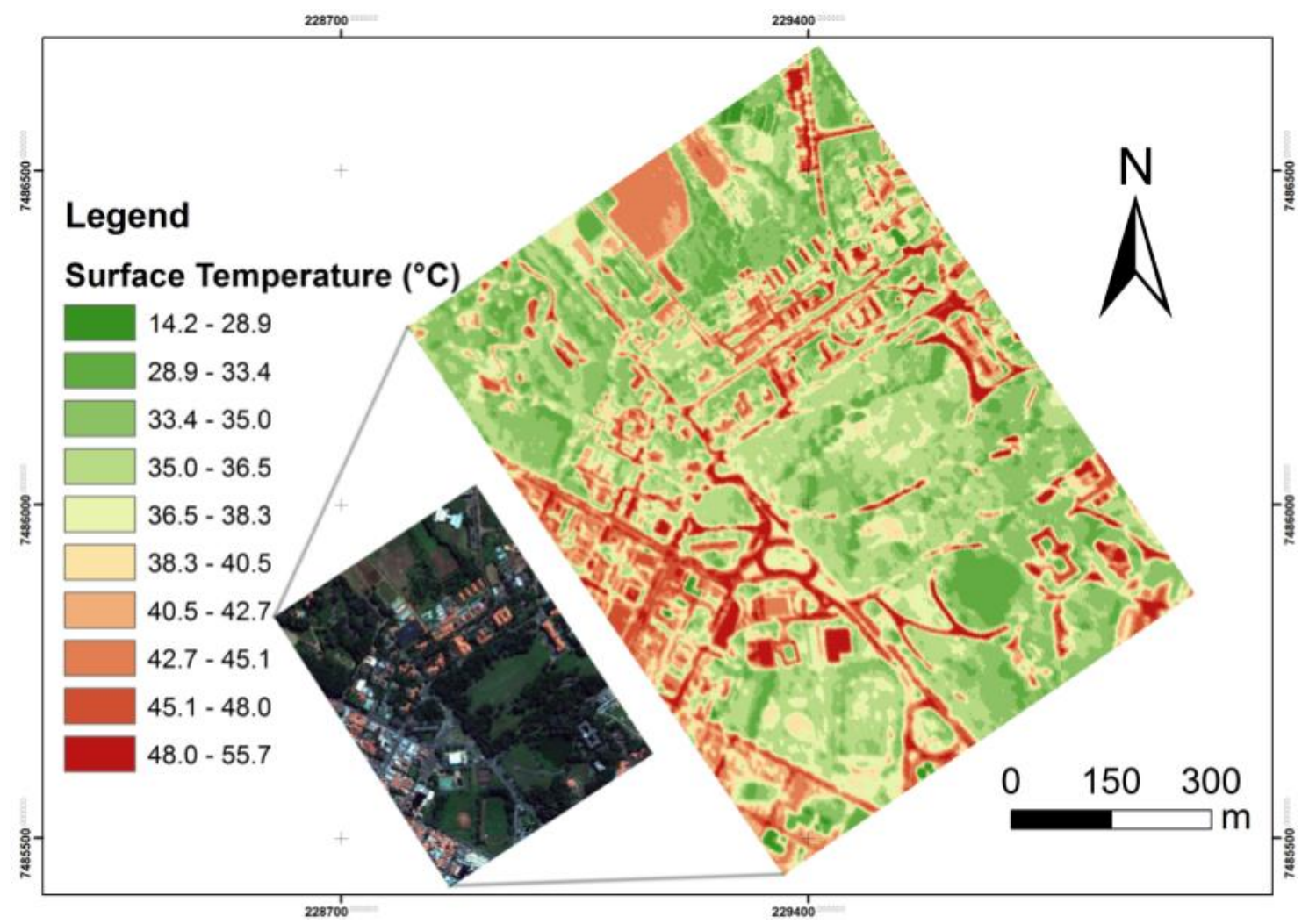

Figura 4: Mapa temático de temperatura de superfície às 14:27, na ESALQ/USP e arredores, com o asfalto atingindo os maiores valores, com pico de $55,7^{\circ} \mathrm{C}$, enquanto que a vegetação apresentou menor amplitude térmica.

Na imagem noturna, às 19:23, verifica-se uma inversão da temperatura de superfície das copas de árvore e corpos d'água $\left(28,6{ }^{\circ} \mathrm{C}\right.$ a $\left.31,9^{\circ} \mathrm{C}\right)$, pois, o que antes era considerado superfícies mais frias, passa a ter temperaturas mais elevadas. Este fato pode ser explicado em função do alto valor do calor específico da água $\left(1,0 \mathrm{cal} \mathrm{g}^{-1}{ }^{\circ} \mathrm{C}^{-1}\right)$, ou seja, a água demora para esquentar e demora para esfriar, liberando o calor lentamente para o ambiente durante a noite. As temperaturas de superfície mais frias são identificadas como telhas e gramados, apresentando valores entre $12,8^{\circ} \mathrm{C}$ e $27,5^{\circ} \mathrm{C}$; quanto ao asfalto, este continuou apresentando os maiores valores, $31,9^{\circ} \mathrm{C}$ a $36,6^{\circ} \mathrm{C}$ (Figura 5). 


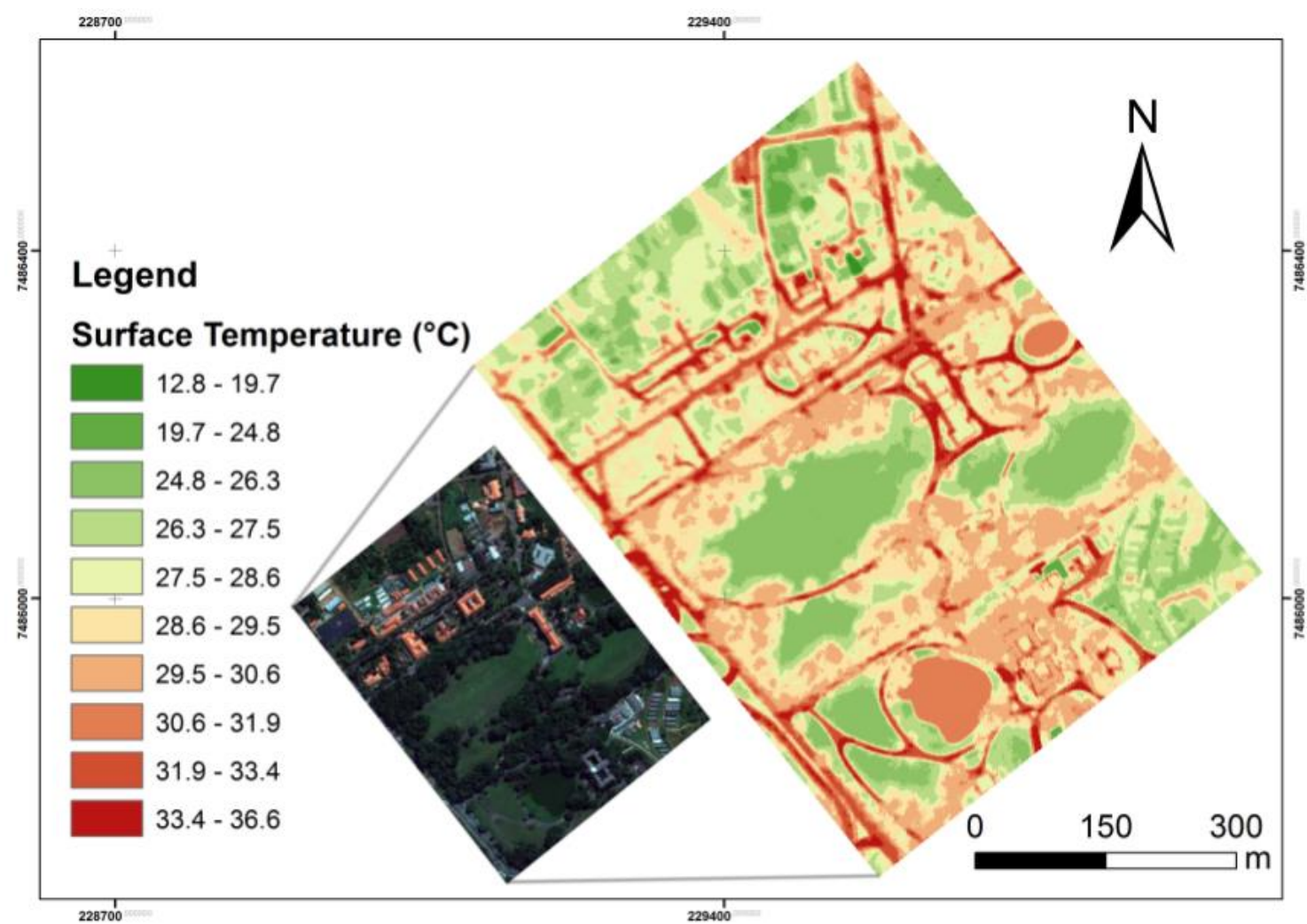

Figura 5: Mapa temático de temperatura de superfície às 19:23, na ESALQ/USP e arredores, na qual se percebe a retenção do calor pelo asfalto no início do período noturno.

Comparando-se a cobertura arbórea nas três imagens, percebeu-se que a temperatura de superfície iniciou com valores amenos pela manhã (8:36), aquecendo-se ao longo do dia e, à noite, permaneceu com altas temperaturas, assim como corpos d'água, resfriando-se lentamente. Quando comparamos os valores observados nas áreas asfaltadas, percebe-se que o asfalto está bem quente às $14: 27$, com máxima temperatura de superfície de $55,7^{\circ} \mathrm{C}$.

A máxima temperatura de superfície encontrada para o asfalto foi de $55,7^{\circ} \mathrm{C}$, em se tratando de dia muito quente, diferentemente do que foi verificado por Gartland (2010) [3], na qual constatou que o asfalto comumente ultrapassa $65^{\circ} \mathrm{C}$. Vale ressaltar que no período noturno o asfalto permaneceu com máxima temperatura de superfície igual a $36,6^{\circ} \mathrm{C}$.

\section{CONCLUSÃO}

Foi possível comparar o comportamento das classes de uso do solo quanto às variações na temperatura de superfície ao longo do dia. $\mathrm{O}$ asfalto, cimento e telhados metálicos elevaram as temperaturas das superfícies e contribuíram para o aquecimento local, enquanto que as copas de árvores, relvados e corpos d'água minimizaram o efeito.

O acompanhamento da variação da temperatura de superfície dos objetos de uma determinada área pode servir de base para análise do efeito da ilha de calor urbano e, assim, verificar quais locais necessitam de intervenções prioritárias que garantam o conforto térmico das pessoas.

As imagens aéreas termais de alta resolução espacial podem ser utilizadas como instrumento de estimativa das temperaturas de superfície, representando uma importante ferramenta para mapeamento do campo térmico urbano. 


\section{AGRADECIMENTOS}

Os autores agradecem à FAPESP (Processo 2009/53931-6) pela compra da câmera termal e respectivos acessórios.

\section{REFERÊNCIAS BIBLIOGRÁFICAS}

1. Oke TR. Initial Guidance to Obtain Representative Meteorological Observations at Urban Sites, Instruments and Observing Methods (IOM) Report No. 81. World Meteorological Organization (WMO). Geneva; 2006. $51 \mathrm{p}$.

2. Nichol JE, Fung WY, Lam K, Wong MS. Urban heat island diagnosis using ASTER satellite images and 'in situ' air temperature. Atmos. res. 2009 Oct: 94 (2): 276-284, doi: 10.1016/j.atmosres.2009.06.011.

3. Gartland L. Ilhas de Calor: como mitigar zonas de calor em áreas urbanas. São Paulo: Oficina de textos; 2010. 248 p.

4. Voogt JA, Oke TR. Complete Urban Surface Temperatures. J. Appl. Meteor. 1997 Sept: 36 (9): 1117 1132, http://dx.doi.org/10.1175/1520-0450(1997)036<1117:CUST>2.0.CO;2.

5. Yu C, Hien WN. Thermal benefits of city parks. Energy build. 2006 Feb: 38(2): 105-120, doi:10.1016/j.enbuild.2005.04.003.

6. Costa AS, Franco IM. Aplicação de imagens termográficas para caracterização do calor urbano. Rev. Ciênc. Amaz. 2013 1(2): 18-26.

7. Leuzinger S, Vogt R, Körner C. Tree surface temperature in an urban environment. Agric. for. meteorol. 2010 Jan: 150 (1): 56-62, doi:10.1016/j.agrformet.2009.08.006.

8. FLIR SC660 specifications. Online Manual; 2009. [acesso em 2015 maio 7]. Disponível em: http://www.flir.co.uk/cs/display/?id=41965.

9. Engenharia de Biossistemas. Posto Meteorológico. [acesso em 2015 maio 7]. Disponível em: http://www.leb.esalq.usp.br/postoaut.html. 